\title{
Investigación
}

\section{La influencia del neoconstitucionalismo en la construcción del precedente judicial en el derecho colombiano}

\author{
The influence of neoconstitutionalism \\ in the construction of judicial precedent \\ in Colombian law
}

Jorge Andrés Páez Quiñones ${ }^{1}$

Recepción: 08/02/2021 • Aprobación: 21/05/2021 • Publicación: 17/11/2021

Para citar este artículo

Páez Quiñones, J. A. (2021). La influencia del neoconstitucionalismo en

la construcción del precedente judicial en el derecho colombiano. Dos mil

tres mil, 23, e319. https://doi.org/10.35707/dostresmil/23319

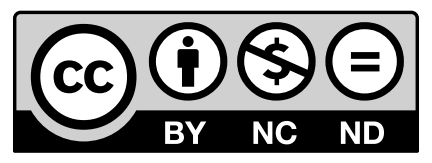

${ }^{1}$ Universidad Cooperativa de Colombia (sede Ibagué). oRcID: 0000-0001-8671-1310. Correo electrónico: jorge.paezq@campusucc.
edu.co 
Resumen. El presente artículo describe y reflexiona sobre el origen y concepto del neoconstitucionalismo en Colombia, para esto se hará una revisión doctrinal y jurisprudencial, buscando delimitar el alcance y consecuencias de esta teoría en nuestro ordenamiento jurídico. También se hace énfasis en la construcción del precedente judicial a la luz de la constitucionalización del derecho, generando un puente crítico que permita al lector entender cómo, por medio de este trasplante jurídico, la Corte Constitucional tomó elementos conceptuales para la interpretación de la Constitución de 1991.

Abstract. This article describes and reflects on the origin and concept of neoconstitutionalism in Colombia, for this a doctrinal and jurisprudential review will be made, seeking to delimit the scope and consequences of this theory in our legal system. Emphasis is also placed on the construction of the judicial precedent in light of the constitutionalization of the law, generating a critical bridge that allows the reader to understand how, through this legal transplant, the Constitutional Court took conceptual elements for the interpretation of the Constitution of 1991.

Palabras claves

Neoconstitucionalismo, teoría del derecho, precedente judicial, trasplantes jurídicos, derechos fundamentales, justiciabilidad.

Key words

Neoconstitutionalism, theory of law, judicial precedent, legal transplants, fundamental rights, justiciability. 


\section{Introducción}

Uno de los temas de mayor interés en la literatura jurídica del derecho constitucional ha sido el denominado neoconstitucionalismo. En el presente escrito se pretende hacer una revisión doctrinal de dicho concepto, pasando por sus orígenes, características y autores relevantes en la consolidación de esta teoría jurídica, que ha generado un impacto importante en América Latina y de la cual Colombia no escapó a su influjo, siendo uno de los países líderes en la región en el estudio y la producción del neoconstitucionalismo tanto a nivel doctrinal como jurisprudencia; esta última por parte de la Corte Constitucional.

Para esto, se explicará el concepto de constitucionalización del derecho, el cual está íntimamente ligado con el neoconstitucionalismo, pasando por la categoría jurídica del precedente judicial. Con esto se pretende exponer cómo, gracias a los trasplantes jurídicos, se modificaron las fuentes del derecho en Colombia, generando un sistema de precedentes que creó un nuevo escenario en el cual la Corte Constitucional introdujo tesis neoconstitucionales en sus providencias; por lo tanto, se pretende crear una reflexión que permita al lector entender los aportes de esta teoría al ordenamiento jurídico colombiano. De ahí que el problema a indagar está en mostrar los aportes que trajo el neoconstitucionalismo a la construcción del precedente y sus consecuencias.

El alcance de estudio del presente artículo es analítico-explicativo; sin embargo, parte de un enfoque descriptivo que da a conocer los elementos básicos del neoconstitucionalismo, haciendo énfasis en la constitucionalización del derecho. De esta forma, el estudio inicia explicando los orígenes del neoconstitucionalismo y su evolución conceptual, revisando los aportes de la doctrina, su llegada al ordenamiento jurídico colombiano y su influencia en las sentencias emanadas por la Corte Constitucional, para finalmente llegar a la conclusión de que esta teoría sí influenció en las decisiones de la Corte Constitucional, quien desde sus primeros años trató de influenciar las relaciones jurídicas, sociales, políticas y económicas, entre otras, desde un enfoque constitucional, al revisar diversas fuentes como la propia jurisprudencia de la Corte Constitucional y reconocidos doctrinantes del derecho constitucional nacional e internacional.

\section{Origen del neoconstitucionalismo}

El neoconstitucionalismo tiene sus orígenes en Italia hacia finales de la década de los años setenta del siglo pasado, específicamente en la escuela Genovesa y de forma concreta por la jurista Susanna Pozzolo (1998):

[...] si bien es cierto que la tesis sobre la especificidad de la interpretación constitucional encuentra partidarios de diversas disciplinas, en el ámbito de la filosofía del derecho viene defendida, en particular, por un grupo de iusfilósofos que comparten un peculiar modo de acercarse al derecho. He llamado a tal corriente de pensamiento neo constitucionalismo. (p. 339). 
Con ello se pretendió explicar una nueva dinámica jurídica que propone controlar las decisiones del poder político de los Estados, soportándose en la obligación de la promoción y la defensa de los derechos fundamentales reconocidos históricamente en los procesos transformadores iniciados con los movimientos y movilizaciones sociales en el mundo. De ahí que se intentó crear un modo de entender aquellas prácticas jurisprudenciales, a raíz de aquellas constituciones surgidas a partir de la Segunda Guerra Mundial, las cuales se adaptaron a la nuevas coyunturas políticas, sociales, económicas y culturales que ya incluían un Tribunal o Corte Constitucional como garantes de la supremacía constitucional y de ir impetrando los principios constitucionales en la legislación.

La tesis neoconstitucional entró a nuestro país a partir de la Constitución de 1991, tal vez por la necesidad de darle un nuevo aire a nuestra legislación y esta se soportó en la constitucionalización del derecho. Ambas corrientes fueron transcendentales en el papel que iba desempeñar la, por entonces, recién creada Corte Constitucional, quien se iba a impetrar de dichas corrientes en, no solo la construcción del precedente judicial, sino en general de varias posturas jurídicas muy ligadas a ellas mediante su jurisprudencia, a veces aplaudida y en otras ocasiones señalada y fuertemente criticada, tal como lo señala Núñez (2012):

El Neoconstitucionalismo es una doctrina alimentada por la Constitucionalización del Derecho, escenario que tiene su causa en la fusión de las tradiciones de las cartas políticas y las constituciones garantizadas. No es el Neoconstitucionalismo el que ha generado el denominado Estado Constitucional de Derecho, sino que, a la inversa, el surgimiento de este ha estimulado la proliferación del amplio espectro de ideas que se albergan (o a veces se estigmatizan) bajo el título de neoconstitucionalistas. (p. 2).

\section{2. ¿Qué es el neoconstitucionalismo?}

El neoconstitucionalismo pretende explicar algunas características uniformes presentadas en los textos constitucionales que surgen a partir de la Segunda Guerra Mundial, de acuerdo con Carbonell (2011):

Se trata de constituciones que no se limitan a establecer competencias o a separar a los poderes públicos, sino que contienen altos niveles de normas "materiales" o sustantivas que condicionan la actuación del Estado por medio de la ordenación de ciertos fines y objetivos. (p. 162).

Este tipo de constituciones con mandatos claros en donde se pueden encontrar un catálogo amplio de derechos, fines del Estado, principios, valores, entre otras series de disposiciones, generando un cambio evidente con respecto a las constituciones de antaño. De acuerdo con Carbonell (2011):

Ejemplos representativos de este tipo de constituciones, en lo que respecta puntualmente a su texto, lo son la Portuguesa de 1976, la Española de 1978, la Brasileña de 1988, la Colombiana de 1991, la Venezolana de 1999 y la Ecuatoriana de 1999. (s.p.). 
La tesis neoconstitucional ha sido planteada por varios autores, algunos de forma directa como Susanna Pozzolo en su texto Neoconstitucionalismo y positivismo jurídico, traducido al español por Palestra Editores en 2011 o Luis Prieto Sanchís con su texto Neoconstitucionalismo, principios y ponderación editado por Ubijus Editorial en México en el año 2011. Además de ello, difundieron sus ideas en conferencias y cátedras universitarias, sin embargo, hay dos textos que son claves para entender el neoconstitucionalismo y su desarrollo en todo Latinoamérica, en primer lugar el libro Neoconstitucionalismo(s), editado por el profesor mexicano Miguel Carbonell en el 2003 y, en segundo lugar, El canon neoconstitucional, editado también por Carbonell en compañía del profesor colombiano Leonardo García Jaramillo, este último hace parte de la serie intermedia de teoría jurídica y filosofía del derecho de la Universidad Externado de Colombia, en donde autores como Paolo Comanducci, Miguel Carbonell, Susanna Pozzolo, entre otros, presentan los componentes del neoconstitucionalismo.

De igual manera, algunos doctrinantes iberoamericanos han planteado los postulados teóricos sobre los cuales se basa el neoconstitucionalismo, tomando como influencia a Robert Alexy, quien en su libro Teoría de los derechos fundamentales plantea la tesis de la ponderación, la cual, al poste, viene a ser una de las armas de batalla de los neoconstitucionalistas para decidir aquellos casos en donde los principios y derechos estén en colisión. Alexy la definió en una ya célebre frase: "Cuando mayor sea el grado de insatisfacción o de detrimento de un derecho o un principio, mayor debe ser la importancia de satisfacer al otro. Esta regla podría denominarse ley de la ponderación" (Alexy, Vázquez, \& Zimmerling, 2005, p. 90).

Por otro parte, también son muy relevantes los escritos de Zagrebelsky (2009), quien en su obra $E l$ derecho dúctil explica cómo nace el estado constitucional, sus características esenciales y enmarca las funciones del juez constitucional, denominándolo hoy en día como los señores del derecho, pues en ellos, en efecto, se dan cita todas las dimensiones del derecho: "La ley, los derechos y la justicia" (p. 150). Esa mirada de Zagrebelsky (2009), entre distinguir el legalismo y dejarlo atrás para dar paso a un verdadero constitucionalismo, tiene su fundamento en los principios de libertad y justicia, los cuales deben guiar al juez constitucional en su tarea interpretativa. Esto llevaría a los neoconstitucionalistas a elogiar su labor antiformalista como magistrado del tribunal constitucional italiano siempre en defensa de los principios constitucionales, pues como Zagrebelsky (2009) lo afirma: "Distinguir los principios de las reglas significa, a grandes rasgos, distinguir la Constitución de la Ley” (p. 110).

Por otro lado, un autor muy importante para el neoconstitucionalismo sin lugar a duda es Dworkin (2002), quien para muchos planteó varios cánones del neoconstitucionalismo en su libro Los Derechos en serio. Es importante precisar que, si bien Dworkin nunca se definió como neoconstitucionalista, varios de sus postulados fueron la inspiración para que muchos autores teorizaran a partir de su nueva concepción del positivismo jurídico o del neoisunaturalismo:

Sería inadecuado omitir el estudio de la teoría elaborada por Ronald Dworkin, que bien podría coincidir con los postulados del neoconstitucionalismo, en específico con la idea de un constitucionalismo de principios. Así, se considera que sí se podrían ubicar las ideas de Ronald Dworkin 
dentro de dicha corriente o, mejor dicho, se deberían utilizar los postulados de la teoría del derecho de Dworkin para entender el neoconstitucionalismo. (Romero, 2017, p. 41).

Algunos autores han planteado clasificaciones de varios tipos de neoconstitucionalismo, ejemplo de ello es el italiano Paolo Comanducci que lo divide en tres: un neoconstitucionalismo teórico, ideológico y metodológico. En el neoconstitucionalismo teórico enmarca autores como Ferrajoli y Zagrebelsky: “[...] aspira a describir los logros de la constitucionalización, es decir, de ese proceso que ha comportado una modificación de los grandes sistemas jurídicos contemporáneos respecto de los existentes antes del despliegue integral del proceso mismo" (Comanducci, 2010, p. 177). El fin de este tipo de neoconstitucionalismo se centra en la necesidad de la positivización y protección de los derechos fundamentales, igualmente, defienden la idea de que en las constituciones deben existir más principios que reglas que le permitan al juez constitucional una interpretación más amplia para garantizar esos derechos fundamentales.

En cuanto al neoconstitucionalismo ideológico se aparta de la corriente constitucionalista, ya que considera que la limitación del poder estatal no es tan trascendente como la garantía de los derechos fundamentales, exponiendo el paso del estado de derecho al estado constitucional, el cual logró consolidarse en Occidente. Por lo cual defiende todo mecanismo que busque la tutela de los derechos fundamentales, considera que el poder legislativo y judicial deben estar encaminados a la garantía de los derechos. Por otro lado, el neoconstitucionalismo ideológico considera de vital importancia la aplicación de la Constitución respecto de la aplicación de la ley, además: "[...] no se limita por tanto a describir los logros del proceso de constitucionalización, sino que los valora positivamente y los defiende" (Comanducci, 2010, p. 179). Finalmente, estaría el neoconstitucionalismo metodológico, que pretende explicar el derecho tal como es y distinguirlo del derecho del deber ser, el máximo exponente para Comanducci es el alemán Robert Alexy y el estadounidense Ronald Dworkin:

El neoconstitucionalismo metodológico sostiene, por el contrario - al menos respecto de situaciones de derecho constitucionalizado, donde los principios constitucionales y los derechos fundamentales constituirían un puente entre derecho y moral-, tesis de la conexión necesaria, identificativa y justificativa, entre derecho y moral. (Comanducci, 2010, p. 181).

De acuerdo con los neoconstitucionalistas, el activismo judicial es una herramienta para lograr los fundamentos de estos postulados, mientras que la jurisprudencia de los tribunales o cortes constitucionales esté en garantía de los derechos y las normas jurídicas se interpreten bajo postulados morales, se justifica su activismo.

\section{La constitucionalización del derecho}

Como lo advierten algunos autores, no es fácil definir la categoría jurídica de constitucionalización del derecho, esto debido a lo amplio e indeterminado que resulta dicho término, además, de que con ella van relacionados varios conceptos jurídicos necesarios en el marco del estudio constitucional, bien lo advierte Suárez-Manrique (2014): 
Hablar del proceso de constitucionalización del derecho resulta un asunto difícil, si no hay un acuerdo sobre nociones generales relacionadas con él. Un diálogo fructífero y dialéctico que desee ser tomado en serio para la comprensión del fenómeno implica un acuerdo mínimo sobre ciertos postulados relacionados con el proceso de constitucionalización. Implica, pues, un acuerdo mínimo, en especial acerca de lo que se entienda por derecho, Constitución, derechos fundamentales y principios. (p. 320).

Sin embargo, hay algunas características propias de esta postura que se pueden definir puntualmente, ejemplo de ello, lo da el profesor francés Favoreu al afirmar: "En el proceso de constitucionalización deben tomarse en consideración, primero, la acumulación de normas constitucionales a través del desarrollo de la justicia constitucional, y luego el mecanismo de difusión de estas normas en el orden jurídico" (Citado por Castañeda, 2010, p. 69). Sobre la acumulación de normas constitucionales, describe que es un fenómeno propio de aquellos estados en donde opera una justicia constitucional implantada y con constituciones posteriores a la Segunda Guerra Mundial. Por otro lado, frente a la acumulación de normas constitucionales, destaca Favoreu que ahora las normas constitucionales no requieren tanto de las leyes para su desarrollo, sino que estas se pueden aplicar directamente; en ese sentido, el control de constitucionalidad será importante porque los tribunales constitucionales por medio de su jurisprudencia serán los encargados de esta tarea:

La impregnación constitucional del orden jurídico va a resultar ser también del hecho que, debido a que la mayoría de las leyes importantes están siendo transmitidas al Consejo constitucional, este va, de alguna manera, a integrar o incorporar la interpretación al texto de estas leyes, usando cada vez más a menudo la técnica de la conformidad bajo reserva. En consecuencia, las leyes van "vinculando" y llevando a cabo cada vez más las normas constitucionales, propagándolas en todo el derecho. (Favoreu, 2001, p. 35).

De este modo, podemos darnos cuenta hacia donde apunta la tesis de la constitucionalización del derecho. Riccardo Guastini propone la existencia de un ordenamiento jurídico constitucionalizado, el cual se debe caracterizar por contar con una constitución invasora, capaz de condicionar la legislación y la jurisprudencia por medio de un control constitucional garantizador de la supremacía de la constitución, impregnada de principios constitucionales, en la cual el Tribunal Constitucional pueda interpretarla, buscando con ello la conexión en relaciones sociales. De allí que Guiastini considera que un ordenamiento jurídico se encuentra debidamente constitucionalizado cuando cumple con unos requisitos mínimos, como son:

1.1 La existencia de una constitución rígida. 1.2 La Garantía jurisdiccional de la constitución. 1.3 La Fuerza vinculante de la Constitución. 1.4 La Sobre interpretación de la Constitución. 1.5 La aplicación directa de las normas constitucionales. 1.6 La interpretación conforme a las leyes. 1.7 La influencia de la Constitución sobre el debate político. En donde las condiciones 1 y 2 son condiciones esenciales, sin ellas no existiría propiamente una constitución, de la 3 a la 7, son suficientes 
para hablar de un grado de constitucionalización y de la 3 a la 5 están extremadamente relacionadas entre sí. (Guastini, 2009, p. 50).

De este modo, se puede observar ese fuerte vínculo entre el neoconstitucionalismo y la constitucionalización del derecho y esto nos va a llevar al escenario del precedente judicial, puesto que este termina siendo una herramienta que permite el accionar de dichas posturas jurídicas. En ese sentido, Luisa Fernanda García considera la intervención del juez constitucional como necesaria en la construcción del principio democrático, de allí que cuente con un amplio margen de discrecionalidad para justificar la supremacía constitucional:

La constitucionalización del derecho en Colombia obedece a una participación activa del juez, en particular del juez constitucional. El precedente judicial fuente del derecho es una muestra de la inclusión del juez en el escenario constitucional como garante de la democracia y del derecho. El ideal democrático incluye irreversiblemente al juez constitucional y sus interpretaciones. La sobreinterpretación del derecho responde a una interpretación amplia de la Constitución y a la construcción de normas que en algo contribuyen a llenar las lagunas del derecho. Con ello, el neoconstitucionalismo, es constitucionalizar el ordenamiento jurídico. (García, 2013, p. 17).

Bajo la visión del autor, se observa el fuerte vínculo entre el neoconstitucionalismo y la constitucionalización del derecho, siendo este último el escenario en el cual se manifiesta el planteamiento neoconstitucional, lo cual ha generado un buen panorama en el derecho constitucional colombiano.

\section{El precedente judicial}

Si bien en este artículo no corresponde hacer una construcción del desarrollo del precedente judicial, por cuanto sería análisis de otro artículo por la rigidez y puntualidad que merece el tema, sí es importante para efectos de entender la problemática planteada, tener un concepto general del precedente judicial.

Desde los primeros fallos emitidos por la Corte Constitucional se dio el trabajo de ir conceptualizando el precedente, en la Sentencia C-104 de 1993, la Corte nos recuerda que el precedente obligatorio es denominado stare decisis en el sistema anglosajón y de allí se apoya para dar a entender que, si bien en el sistema de tradición jurídico romana la jurisprudencia juega un papel secundario, en el caso de la jurisprudencia de la Corte Constitucional esto no es así, por ello, basada en el artículo 243 de la Constitución, desarrollado en el artículo 23 del Decreto 2067 de 1991, el alto tribunal constitucional consideró necesario en nuestro ordenamiento jurídico la finalidad de la unificación jurisprudencial:

La uniformidad no es un fin despreciable. Ella busca garantizar los siguientes altos objetivos:

1. Asegurar la efectividad de los derechos y colabora así en la realización de la justicia material —art.

2.0 $\mathrm{CP}$-.

2. Procurar exactitud. 
3. Conferir confianza y credibilidad de la sociedad civil en el Estado, a partir del principio de la buena fe de los jueces - art. $83 \mathrm{CP}-$

4. Unificar la interpretación razonable y disminuye la arbitrariedad.

5. Permitir estabilidad.

6. Otorgar seguridad jurídica materialmente justa.

7. Llenar el vacío generado por la ausencia de mecanismos tutelares contra providencias judiciales. (Corte Constitucional, Sentencia C-104, 1993, s.p.).

Si bien es cierto, de forma tibia la Corte inicialmente no le dio el carácter obligatorio al precedente a como hoy se conoce, ni se hizo una definición que describiera las características de esta. Ya en la sentencia SU-047 de 1997 la Corte planteó la necesidad de respeto del precedente, considerando que este cumple con cuatro funciones claras: seguridad jurídica y coherencia del sistema jurídico, protección de la libertad ciudadana y permitir el desarrollo económico, cumplir con el principio de igualdad y, finalmente, como mecanismo de control de la actividad judicial. En este fallo la Corte concluye:

El respeto al precedente impone a los jueces una mínima racionalidad y universalidad, ya que los obliga a decidir el problema que les es planteado de una manera que estarían dispuestos a aceptar en otro caso diferente pero que presente caracteres análogos. Por todo lo anterior, es natural que en un Estado de derecho, los ciudadanos esperen de sus jueces que sigan interpretando las normas de la misma manera, por lo cual resulta válido exigirle un respeto por sus decisiones previas. (Corte Constitucional, Sentencia C-047, 1997, s.p.).

Hoy se tiene una definición más completa de lo que es un precedente judicial, gracias a la construcción jurisprudencial que llevó a cabo la Corte Constitucional en todos estos años:

El precedente es conocido como la sentencia o el conjunto de ellas, anteriores a un caso determinado, que por su pertinencia y semejanza en los problemas jurídicos resueltos, debe necesariamente considerarse por las autoridades judiciales al momento de emitir un fallo. (Corte Constitucional, Sentencia SU-053, 2015, s.p.).

La construcción del precedente en Colombia no fue tarea fácil, se han dado muchas críticas desde la doctrina, con argumentos muy fuertes, como los planteados en el libro El precedente judicial en Colombia: papel y valor asignados a la jurisprudencia de Jaramillo y Tamayo (2002). Este último señala que la Corte Constitucional planteó el precedente judicial desconociendo los mandatos del artículo 230 de la Constitución, obligando a los jueces y otras altas cortes a fallar en razón a la ratio decidendi cuando, a su juicio, una lectura de dicho artículo le da el carácter de fuente subsidiaria, lo cual genera conflictos pues, a su juicio, abogados y jueces pueden estar en desacuerdo con el precedente en casos concretos: 
Es imposible la creación de una línea doctrinal y jurisprudencial seria y más o menos hilvanada y uniforme, pues ya no se trata de interpretar el orden jurídico vigente, sino de estudiar los precedentes jurisprudenciales, con su carga de subjetivismo axiológico carente de respaldo normativo. (Jaramillo \& Tamayo, 2002, p. 5).

Por consiguiente, nació en Colombia un debate iusteórico entre dos tendencias, por un lado, quienes defienden el precedente y, por otro lado, quienes lo desaprueban. Esto a un punto muy álgido en el debate entre Diego López Medina y Javier Tamayo Jaramillo, generando varias columnas en el conocido periódico Ámbito Jurídico con réplicas y contrarréplicas (López, 2011). El problema en sí está en un cambio en el sistema tradicional de las fuentes del derecho, pasando la jurisprudencia de ser criterio auxiliar a criterio de obligatorio cumplimiento, y constituyendo el denominado precedente judicial. Esto generó una nueva tendencia en nuestro país, a la que se le conoce como formalismo jurídico:

Por formalismo, entiendo el hábito intelectual de los estudiosos de derecho para quienes un problema jurídico se resuelve predominantemente o exclusivamente, mediante el análisis, más o menos detallado, de las reglas de origen legislativo que se han promulgado al respecto. (López, 2006, p. 226).

Colombia venía de una larga tradición del sistema civil law, en donde la Ley era la fuente formal del derecho y la jurisprudencia, se consideraba fuente auxiliar, contrario a lo que sucede en el sistema de derecho común. Esta dicotomía llevó a una transformación del sistema de fuentes, en la cual la Corte Constitucional debió aplicar una interpretación sistemática del artículo 230 de la Constitución para variar el sistema de fuentes y darle una nueva lectura al sistema constitucional colombiano, generando una lucha por la consolidación del precedente y el respeto al mismo de toda la comunidad jurídica. Al respecto comenta Lancheros-Gámez (2012):

Una definición simplista podría caracterizar al sistema constitucional colombiano como uno que se encuentra a medio camino entre el common law (particularmente el de estados Unidos) y el civil law, que puede identificarse fácilmente a partir de notas de uno u otro sistema y que no merece particular atención al no pertenecer a ninguno de ellos por completo. Sin embargo, lo que ha sucedido en Colombia es que se ha producido un peculiar mestizaje de tradiciones jurídicas que es más que la simple mezcla de ellas. El Derecho constitucional colombiano ha llegado a tener una identidad propia que lo hace diferente, peculiar y, si se quiere, atractivo para aquellos que deseen observar cómo la jurisprudencia puede complementar y, en algunos casos, desplazar a la ley como fuente principal de Derecho en un sistema jurídico de origen europeo continental. (s.p.).

Por otra parte, la Corte Constitucional fue consolidando su tesis sobre la necesidad de darle un carácter vinculante al precedente, de ahí que a partir del artículo 230 de la Constitución le dio un significado amplio bajo el cual no solo lo dispuesto en las normas creadas por el legislador son las que deben aplicar los jueces en sus providencias. A esto le agregó la interpretación que se haga de la misma en sus sentencias, tratando de conectar sus fallos y creando nuevas disposiciones, lo cual Blanco Cortina comenta: 
De tal suerte que las leyes no son solo las palabras del legislador, sino que son las palabras del legislador más la interpretación que los jueces hacen de ellas, en aras de fijar su sentido preciso para facilitar la comprensión del mensaje normativo -en términos de prohibición, permisión u obligación de ciertas conductas- por parte de los receptores naturales del mensaje: los ciudadanos. (Blanco, 2016, p. 113).

De esta forma, se fue construyendo, a partir de la interpretación sistemática de la Corte Constitucional, todo un andamiaje en pro del precedente en nuestro sistema de fuentes, conllevando al principio de la seguridad jurídica y, por ende, a interpretaciones vinculantes que se generan en la ratio decidendi de sus fallos, la cual, a juicio de la Corte, "tiene fuerza y valor de precedente para todos los jueces en sus decisiones, por lo que puede ser considerada una fuente de derecho que integra la norma constitucional" (Corte Constitucional, Sentencia T-292 de 2006, s.p.).

\section{La entrada del neoconstitucionalismo a Colombia}

Algunos autores como Bernal Pulido consideran que el neoconstitucionalismo entró a Colombia con la actual Constitución:

La Constitución Política de 1991 determinó la entrada en Colombia al neoconstitucionalismo. Esta corriente alude a un modelo de organización política denominado Estado constitucional. La principal ley de construcción de este tipo de Estado es el reconocimiento de la supremacía de la Constitución y de los derechos fundamentales. Este reconocimiento es correlativo a la creación de una Corte Constitucional, es decir, un tribunal especializado para la interpretación y concreción de la Constitución. A su vez, esta creación implica una modificación en el sistema de fuentes del derecho y en el equilibro de los poderes del Estado. (Bernal, 2008, p. 149).

De igual manera, el neoconstitucionalismo entró a ayudar a consolidar algunas de las figuras nuevas de la actual Constitución, algunas desarrolladas por la jurisprudencia de la Corte Constitucional, ejemplo de ello es la tesis del núcleo esencial o duro de los derechos, el alcance de los derechos fundamentales y la consolidación del Estado social de derecho, como bien lo anota García (2008), tales niveles desarrollados en nuestro contexto son:

La nueva Constitución de 1991, las renovadas prácticas jurisprudenciales de la Corte Constitucional -Y su misma creación- y los desarrollos teóricos llevados a cabo por profesores y académicos de las principales facultades de derecho que han contribuido de singular forma con la evolución y sofisticación paulatinas de nuestro derecho. De aquí se derivará que el neoconstitucionalismo en Colombia sí supone una novedad y una particular significación dentro de la concepción del Estado social de derecho en las facultades. (s.p.).

Por otra parte, Hoyos (2015) plantea la existencia de dos tipos de neoconstitucionalismo, uno de corte norteamericano y otro europeo, a este último se le conoce como neoconstitucionalismo ideológico y en este se encuentra Colombia: 
Su origen histórico está en las valiosas elaboraciones jurisprudenciales del tribunal constitucional alemán en los primeros años de labor jurisprudencial con posterioridad de la llamada Ley de Bonn, aunque su conceptualización y denominación son más recientes y han ocurrido principalmente en Italia y España y por Latinoamérica Colombia y México. (p. 137).

Esto, sin duda, nos da a entender que el neoconstitucionalismo llega al país por los famosos trasplantes jurídicos a partir de la actual Constitución Política y que fue alimentada en el ámbito judicial, doctrinal y académico, tal como lo afirma Hoyos (2015). La aparición del neoconstitucionalismo ideológico en Colombia ha sido posible gracias a un proceso de trasplante jurídico constante, el cual ha sido fortalecido por la labor vanguardista y liberal de la Corte Constitucional, sin dejar de mencionar algunas facultades de Derecho del país inexcusablemente capitalinas.

El neoconstitucionalismo ha sido un apoyo en decisiones de la Corte Constitucional, en algunos casos han sido materia de obiter dicta, como ejemplo está la Sentencia T-627/10, allí decide la Corte una acción de tutela frente a la posibilidad de acceder a la pensión vitalicia por parte de los accionantes, dado que hacían parte del régimen especial de magistrados de la Corte Suprema de Justicia y el Consejo de Estado, antes de la entrada en vigor de la Ley 4 de 1992. En dicha providencia se cita al autor Prieto (1997).

Así mismo, una particularidad concreta del Estado social de derecho que introdujo el Constituyente de 1991, respecto del marco constitucional anterior, es que la Constitución además de ser suprema en el ordenamiento jurídico, tiene carácter vinculante o fuerza normativa, lo cual significa que vincula a todo el poder público. Dicho en otros términos, no es apenas un referente formal o retórico en el sistema de fuentes formales del derecho, sino que se trata de una verdadera norma jurídica. Carácter vinculante de la constitución que, para el neoconstitucionalismo, significa que además de regular la organización del poder y las fuentes del derecho, genera de modo directo derechos y obligaciones inmediatamente exigibles.

En la Sentencia C-076 del 2018 se analizó la constitucionalidad del Acto Legislativo 05 del 29 de noviembre de 2017 en el cual se buscaba asegurar el uso exclusivo de las armas por parte del Estado, parte del famoso fast track. Analizando la norma en cuestión, la Corte cita a Guastini, uno de los autores referentes del tema: "Guastini explica que la Constitución no solo debe ser entendida en el sentido clásico, como límite al poder político, sino que adicionalmente es fuente del derecho para disciplinar directamente las relaciones entre el Estado y los ciudadanos" (Corte Constitucional, Sentencia C-076, 2018, s.p.). Por otro lado, la edificación del concepto de principios y valores constitucionales por parte de la Corte Constitucional se debe en buena medida a esta teoría, la ponderación como una herramienta para resolver los casos difíciles y especialmente la construcción de los derechos sociales fundamentales:

La Corte Constitucional colombiana en general y su jurisprudencia en materia de derechos sociales en particular se han convertido en uno de los íconos del neoconstitucionalismo progresista. En un giro paradójico de la historia social y jurídica, precisamente en unos de los países con violaciones 
más graves de los derechos humanos ha pasado de ser exportador neto de jurisprudencia constitucional y de innovaciones institucionales para asegurar el cumplimiento de decisiones ambiciosas sobre derechos sociales. Hoy en día, en efecto, la jurisprudencia de la Corte es citada con entusiasmo por tribunales latinoamericanos y de otras partes del mundo, y suele ser incluida en estudios comparados sobre la protección de los derechos sociales. (Rodríguez, 2009, p. 40).

Con todas las críticas que pueden caer por el excesivo uso de los postulados del neoconstitucionalismo, la Corte, desde sus primeros fallos, inició un nuevo papel que con la Constitución de 1886 no existía y era ese rol de darle sentido a las normas constitucionales. La teorización de doctrinas como la del derecho viviente han acercado al juez a la sociedad, marcando un referente que, a pesar de los casos de posible corrupción en el seno de la Corte frente a la selección del reparto de las tutelas, es cierto que la Corte goza de un gran prestigio en la sociedad colombiana y esto en parte se debe al papel que juega al darle una interpretación efectiva a las normas constitucionales. Desde aquella famosa Sentencia T-406 de 1992 ya la Corte daba a entender cuál iba a ser su rol como guardián de la Constitución: "El nuevo papel del juez en el Estado social de derecho es la consecuencia directa de la enérgica pretensión de validez y efectividad de los contenidos materiales de la Constitución" (Corte Constitucional, Sentencia T-406, 1992, s.p.).

Debido a estas posturas de la Corte Constitucional, el querer defender los derechos fundamentales por encima de cualquier postura ideológica y económica, no se habla de la entrada, al menos desde lo jurisprudencial, del estado constitucional a nuestro país. En dicha tarea varios sectores se han enlazado en defender esta tesis, sin necesariamente encuadrarse como neoconstitucionalistas, Velasco y Llano (2015) destacan que dicha teoría se fue dando en Colombia de manera lenta, tímida y paulatina, aun así, se reconoce a la Corte como creadora de derechos, generando un nuevo modo de ver el derecho frente a las posturas ideológicas de antaño, ante lo cual, el estado constitucional ha generado varios adeptos:

Para la implementación parcial de este modelo de Estado, no solo fue esencial la Corte Constitucional, pues las universidades de élite también han desempeñado un destacado papel en el avance del modelo desde las publicaciones jurídicas en las que se amplía la teoría del Derecho, ya que se introducen al país textos con postulados innovadores, diferentes al legalismo y formalismo jurídico. (Velasco \& Llano, 2015, p. 69).

Algunos autores como Hoyos (2015) han analizado los aportes del modelo neoconstitucionalista, siempre enfocado en una herramienta que ha tenido la justicia constitucional en el ordenamiento jurídico colombiano, muy ligado a los avances en materia de derechos contemplados en el marco del trabajo hermenéutico llevado a cabo por la Corte Constitucional, de ahí que Hoyos (2015) afirme:

[...] de esta forma y desde el neoconstitucionalismo ideológico en nuestro país, como ideo-

logía y método de la interpretación constitucional en Colombia, la importancia de la Corte 
Constitucional en estos últimos diez años de desarrollo jurisprudencial se ha especializado en 1) defender la constitución y trasplantar mediante su jurisprudencia las corrientes iusteóricas del derecho, que han consentido posicionar el neoconstitucionalismo ideológico en Colombia; 2) Establecer jurisprudencialmente el concepto de justicia constitucional, propio del neoconstitucionalismo y la teoría de los derechos fundamentales, donde en Colombia ha conseguido la identificación, creación y protección de los derechos fundamentales y 3 ) fortalecer la teoría del precedente, la proporcionalidad y el principio de progresividad de los derechos fundamentales, que han alcanzado a custodiar el mantenimiento del núcleo duro de los derechos fundamentales que avala en condiciones de igualdad la Constitución Política. (pp. 62-63).

Finalmente, cabe destacar que del neoconstitucionalismo se ha generado toda una cultura jurídica, un nuevo análisis de las relaciones entre la persona y el Estado, en donde la Constitución tiene una mirada desde lo ideológico tendiente a la implementación de unos principios constitucionales a la luz de los derechos fundamentales. Esta teoría ha tenido su aporte a nuestro ordenamiento jurídico, con varias falencias, hoy se habla de una crisis del modelo neoconstitucionalista y de nuevas variantes como el nuevo constitucionalismo latinoamericano o del Estado plurinacional, sin embargo, siempre es bienvenida la reflexión sobre el desarrollo de la arquitectura constitucional, más en tiempos en donde se avecinan nuevos cambios. El Estado social de derecho colombiano no se ha podido desarrollar de la mejor manera y se deben crear nuevas estrategias para superar los problemas que se originan por la actual pandemia, tal vez, revisando la teoría neoconstitucional con todas sus características, se encuentren elementos de juicio para replantearlo.

\section{Conclusiones}

La tarea de la Corte Constitucional no es nada fácil, en una sociedad tan diversa y con tantas complejidades sociales, políticas y económicas, el papel de la Corte es garantizar en lo posible los derechos fundamentales de todos los colombianos, tratando de generar la supremacía constitucional mediante su jurisprudencia. En ese sentido, el neoconstitucionalismo ha dado herramientas en la construcción del precedente judicial en Colombia, que no han dejado indiferente a nadie, generando todo tipo de críticas por parte de la doctrina nacional.

Como cualquier institución, seguramente ha cometido errores en algunas decisiones y posiblemente algunos fallos han quedado sin el grado de eficacia deseado, sin embargo, considero que la tesis neoconstitucional ha ayudado en buena parte a la construcción de una jurisprudencia sólida basada en el respeto a la dignidad humana y el principio democrático. Aun así, claramente no existe una filosofía marcada en la Corte Constitucional, el neoconstitucionalismo es apenas uno de las muchas tendencias jurídicas en el pensamiento de algunos magistrados que han pasado por la Corte, sin ser esta la única que ha marcado en su labor hermenéutica pero, sin lugar a dudas, esta ha sido una de las más marcadas en la construcción teórica de algunos temas relevantes de la doctrina constitucional como la constitucionalización del derecho, el desarrollo 
de los principios constitucionales, especialmente aquellos creados por vía jurisprudencial, la consolidación de los derechos fundamentales y de la justicia constitucional, que en estos treinta años de la actual constitución ha consolidado a la Corte Constitucional como un referente para todos los colombianos que ven en ella un guardián de la Constitución.

$\mathrm{Si}$ bien es cierto que en algunos casos las críticas al neoconstitucionalismo por lo difuso de su mensaje terminan siendo apropiadas, negar su incursión y aporte no solo en el ordenamiento jurídico colombiano, sino también en el español, italiano y en buena parte de Latinoamérica sería ineludible cuando diversos autores y tribunales constitucionales han citado los cánones neoconstitucionales dentro de sus quehaceres y competencias. Lo cual conllevó a este análisis en pro de identificar los patrones y legado de la tesis neoconstitucional en Colombia, del cual el precedente judicial terminó jugando un papel importante en la consolidación como fuente primaria, lo que a la postre termina siendo uno de los hechos más notorios en el rol de la Corte Constitucional en nuestro país. A pesar de los descontentos de un sector de la doctrina nacional, hoy el precedente se muestra de manera sólida y consolidada y es aplicada por la gran mayoría de jueces y abogados en su ejercicio profesional, al punto que es explicado en un buen número de facultades de Derecho del país, siendo objeto de estudios y análisis como el que se ha prestado en estas líneas.

\section{Referencias}

Alexy, R., Vázquez, R., \& Zimmerling, R. (2005). Teoría del discurso y derechos constitucionales. Ciudad de México, México: Distribuciones Fontamara.

Asamblea Nacional Constituyente. (1991). Constitución Política de Colombia, Santa Fe de Bogotá, Colombia: Legis.

Bernal Pulido, C. (2008). El derecho de los derechos escritos sobre la aplicación. Bogotá, Colombia: Universidad Externado.

Blanco Cortina, D. (2016). Sobre el precedente judicial y su obligatoriedad. Una revisión de la jurisprudencia reciente. Misión Jurídica, 9(10), 111-127. https://doi.org/10.25058/1794600X.120

Carbonell, M. (2010). El neoconstitucionalismo: significado y niveles de análisis. En M. Carbonell \& L. García Jaramillo (Eds.), El canon neoconstitucional, (pp. 157-171).

Castañeda Infante, P. E. (2010). La constitucionalización del derecho en la sociedad capitalista. Derecho $y$ Realidad, 8(16), 67-77. Recuperado de https://revistas.uptc.edu.co/index.php/derecho_realidad/ article/view/4934

Colombia. Ley 4 de 1992. Mediante la cual se señalan las normas, objetivos y criterios que debe observar el Gobierno Nacional para la fijación del régimen salarial y prestacional de los empleados públicos, de los miembros del Congreso Nacional y de la Fuerza Pública y para la fijación de las prestaciones sociales de los Trabajadores Oficiales y se dictan otras disposiciones, de conformidad con lo establecido en el artículo 150, numeral 19, literales e) y f) de la Constitución Política. Recuperado de https://www.mineducacion.gov.co/1621/articles-90451_archivo_pdf.pdf 
Colombia. Decreto 2067 (2014). Por el cual se dicta el régimen procedimental de los juicios y actuaciones que deban surtirse ante la Corte Constitucional. Presidente de la Republica. Recuperado de https:// www.corteconstitucional.gov.co/lacorte/DECRETO\%202067.php

Comanducci, P. (2010). Constitucionalización y neoconstitucionalismo. En M. Carbonell \& L. García Jaramillo (Eds.), El canon neoconstitucional, (pp. 173-190). Madrid, España: editorial Trotta.

Dworkin, R. (2002). Los derechos en serio. Barcelona, España: Ariel.

Favoreu, L. J. (2001). La constitucionalización del derecho. Revista de Derecho, 12(1), 31-43. Recuperado de http://revistas.uach.cl/index.php/revider/article/view/2866

García Jaramillo, L. (2008). El "nuevo derecho" en Colombia: ¿entelequia innecesaria o novedad pertinente? Revista de Derecho, (29), 289-330. Recuperado de http://www.scielo.org.co/pdf/dere/ n29/n29a12.pdf

García López, L. F. (2013). ¿Ideal democrático? Del activismo judicial a la constitucionalización del derecho. Civilizar: Ciencias Sociales y Humanas, 13(25), 17-32. https://doi.org/10.22518/16578953.126

Guastini, R. (2009). La constitucionalización del ordenamiento jurídico: el caso italiano. En M. Carbonell (Ed.), Neoconstitucionalismo (s), (pp. 49-74). Madrid, España: Trotta.

Hoyos Rojas, L. M. (2015). Neoconstitucionalismo ideológico y constitucionalismo multinivel. Bogotá, Colombia: Editorial Temis.

Jaramillo Jaramillo, C. I., \& Tamayo Jaramillo, J. (2002). Precedente judicial en Colombia. Papel y valor asignados a la jurisprudencia. Bogotá, Colombia: Pontificia Universidad Javeriana.

Lancheros-Gámez, J. C. (2012). El precedente constitucional en Colombia y su estructura argumentativa. Síntesis de las experiencias de un sistema de control mixto de constitucionalidad a la luz de la sentencia T-292 de 2006 de la Corte Constitucional. Díkaion, 21(1), 159-186. https://doi.org/10.5294/ dika.2012.21.1.5

López Medina, D. (2006). El Derecho de los jueces. Bogotá, Colombia: Legis.

López Medina, D. (13 de junio de 2011). Igualdad y precedente: El argumento contra Tamayo. Recuperado de https://www.ambitojuridico.com/noticias/constitucional-y-derechos-humanos/igualdad-yprecedente-el-argumento-contra-tamayo

Núñez Leiva, J. I. (2012). Constitución, neoconstitucionalismo y lagunas jurídicas (normativas y axiológicas). Estudios constitucionales, 10(2), 511-532. http://dx.doi.org/10.4067/S0718-52002012000200013

Pozzolo, S. (1998). Neoconstitucionalismo y especificidad de la interpretación constitucional. Doxa, 2(21), 339-353. https://doi.org/10.14198/DOXA1998.21.2.25

Prieto Sanchís, L. (1997). Constitucionalismo y positivismo. Ciudad de México, México: Distribuciones Fontamara. Recuperado de https://www.corteidh.or.cr/tablas/25304.pdf

Rodríguez Garavito, C. (2009). La globalización del estado de derecho: El neoconstitucionalismo, el neoliberalismo y la transformación institucional en América Latina. Bogotá, Colombia: Universidad de los Andes.

Romero Martínez, J. M. (2017). Estudios sobre la argumentación jurídica principalista. Bases para la toma de decisiones judiciales. Ciudad de México, México: Universidad Nacional Autónoma de México. 
Sentencia T-406 de 1992. Corte Constitucional de Colombia. Magistrado Ponente: Ciro Angarita Barón. Recuperado de https://www.corteconstitucional.gov.co/relatoria/1992/T-406-92.htm

Sentencia C-104 de 1993. Corte Constitucional de Colombia. Magistrado Ponente: Alejandro Martínez Caballero. Recuperado de https://www.corteconstitucional.gov.co/relatoria/1993/C-104-93.htm

Sentencia C-047 de 1997. Corte Constitucional de Colombia. Magistrados Ponentes: Alejandro Martínez Caballero y Carlos Gaviria Díaz.

Sentencia T-292 de 2006. Corte Constitucional de Colombia. Magistrado Ponente: Manuel José Cepeda. Recuperado de https://www.corteconstitucional.gov.co/relatoria/2006/t-292-06.htm

Sentencia T-627 de 2010. Corte Constitucional de Colombia. Magistrado Ponente: Juan Carlos Henao.

Sentencia SU-053 de 2015. Corte Constitucional de Colombia. Magistrada Ponente: Gloria Stella Ortiz Delgado. Recuperado de https://www.corteconstitucional.gov.co/relatoria/2015/su053-15.htm

Sentencia C-076 de 2018. Corte Constitucional de Colombia. Magistrado Ponente: Alberto Rojas Ríos. Recuperado de https://www.corteconstitucional.gov.co/relatoria/2018/C-076-18.htm

Suárez-Manrique, W. Y. (2014). La constitucionalización del derecho en el ordenamiento jurídico colombiano. Vniversitas, 63(129), 317-351. https://doi.org/10.11144/Javeriana.VJ129.cdoj

Velasco Cano, N., \& Llano, V. (2015). Teoría del derecho, neoconstitucionalismo y modelo de estado constitucional en el contexto colombiano. Novum Jus: Revista Especializada en Sociología Jurídica y Politica, 9(2), 49-73.

Zagrebelsky, G. (2009). El derecho dúctil. Ley, derechos, justicia. Madrid, España: Trotta. 